necessary or attempted. I am aware this will at present hardly tind general favour. I am, however, certain of my fact, and therefore state it boldly."

I invite your attention to the tone and style of this. I have read the works of our greatest surgeons, but I can remember no such assumption of authority on their part. They are masters of their subject-and therefore write modestly. Now how are Dr. Arnott's aphorisms supported ? Where are his facts? What is bis authority? When I know that every practical surgeon is fully aware, that many instances of wounds of the palmar vessels occur in which hæmorrhage can only be arrested by "deligation of the arterial trunks on the cardiac aspect." When I know that for some of these cases, Liston and others recommended that the brachial should be tied; when I know that the radial and ulnar arteries are frequently tied by our best surgeons, after all other means short of this proceeding have failed in their hands, I may justly doubt the authority of Dr. Arnott, unsupported as it is by any recorded facts. To shew that pressure succeeds in some cases, is very different from proving it to be efficient in all. Dr. Arnott may justly retort, that he has a right to his opinion. True, Sir, but we want evidence of his ability to form one.

All the rest of his letter might be easily reduced to the same level, but I forbear.

If Dr. Arnott reads this letter, I trust he will not misinterpret my motive. He threatens us with another communication upon "Wounds of the hand, that organ of so many uses." Should he carry his intention into effect, I trust he will either substantiate or retract what he has written in his former communication.

I am, Sir, your obedient servant,

WM. StanWell, House-Surgeon.

St. Bartholomew's Hospital, August, 1855.

\section{PURGATIVES AFTER OPERATION FOR HERNIA.}

To the Editor of THE LANCET.

SIR, - Having read a report of a successful case of femoral hernia by Mr. Neate, which appeared in THE LANCET of the 11th inst., I have felt somewhat surprised that no remarks have been made on the immedlate employment of purgatives after the operation, in the form of castor oil and tincture of rhubarb.

I am fearful that a successful case of this kind may strengthen in the minds of young practitioners a preference for the mode of practice, one which $I$ know is strictly accord ing to the rules formerly inculcated in the schools on this matter. For my own part, I have broken through the routine method of ordering a purge immediately after an operation for hernia, and am in the habit of substituting a full dose of opium on the principle that if any part is too irritable, (and who will say that the parts are not so in hernia?) common sense says, quiet that irritability, and leave Nature to do the rest.

Knowing that any observation tending to upset established maxims (dogmas?) does but promote free enquiry and so elici truth, I am bound to say that my conclusion is drawn from an experience met with in country practice, in which one-third of the population over the age of forty is ruptured. I have operated on seven cases and without one death. In only one did I give purgatives, which I soon had cause to regret, as it was the only one which afforded me any anxiety; in the rest I einployed the simple treatment alluded to above.

I am, Sir, yours very respectfully, John Dawson, M.R.C.S, L.S.A.

Tolleshunt D'Arcy, Essex, August, 1855.

\section{OPERATION FOR STRICTURE.}

\section{To the Editor of THE LANCET.}

SrR, - The perinæal section of Mr. Syme is unquestionably a most important improvement in the treatment of aggravated cases of "impermeable stricture of the uretha." The far greater adoption amongst surgeons of this external division to the internal division of the late Mr. Stafford (and of M. Reybard more recently) is indicatory of its superiority.

Now, it has struck me, whether, perhaps, an intermediate species of operation might not be advantageously substituted for either of the above operations, viz, a subcutaneous division of the stricture on a Syme's staff? The only objection that I see to this method is the liability to urinary extravasationan objection, however, that applies equally to Stafford's operation, whilst the one I propose, I conceive to be superior to this latter, in combining the definite certainty of division of Syme's operation without the extent of division of the soft parts. I apprehend, however, the passage of a full-sized instrument would obviate any such risk. We daily see subcutaneous divisions of tendons and muscles heal by the first intention, although it is true that here we have not the additional circumstance of the possibility of presence of a foreign liquid. However, practical experience can alone decide practical questions. Indeed, I am not yet prepared to speak to the practicability of the operation at all; but, in the meantime, have ventured to throw out the preceding suggestions to operating surgeons.

I remain, Sir, yours, \&c.,

J. ZaChaRIAH LAURENCE, F.R.C.S.

August, 1855.

\section{THE HOSPITALS IN THE EAST.}

\section{[FROM OUR OWN CORRESPONDENT.]}

HA ving had an opportunity of visiting Varna, so noted from the number of British and French soldiers who died of cholera there last year, I took occasion to visit the hospitals which give accommodation to the sick and wounded in the Crimea, of which there are British, French, and Turkish. The British and Turkish hospitals are for the reception of the sick and wounded of Omar Pasha's army, and the French have received recently 800 patients, chiefly those wounded at the Mamelon and Malakoff attacks.

In the present communication I will confine myself to a description of the English hospitals and the doings of its staff, and on a future occasion I will give such information as to the French and Turkish hospitals, and the cases contained therein, as may appear necessary.

Although the experience of the medical officers sent out to join Omar Pasha's army has been of short duration, yet I feel certain that many in England will be glad to hear of their doings. It is now three months since the hospital at Varna was organized and divided into a General Military Hospital and a Convalescent Hospital. The General Hospital is placed near the large military barracks on the Schumla road, and was formerly the residence of Islam Pasha. It is capable of holding 200 patients, and 600 have already been admitted since the loth of May of the present year. It is certainly not a model of an hospital, as far as construction is concerned, but for present use answers well. The Turkish authorities have placed at the disposal of the medical officers a portion of the barracks capable of containing 800 patients, but their offer has not been accepted, and it will not be occupied as an hospital until such alterations have been carried out as are absolutely necessary; for it was here that so many deaths from cholera took place amongst the English soldiers.

At present there are 150 patients under treatment in the Town Hospital, and 240 in the Convalescent Hospital. Owing to the want of accommodation for the sick in the hospitals, many cases, chiefly those of mild scurvy, are sent to the neighbouring villages. The cases, when admitted, are generally in a very unsatisfactory condition, and the first patients were in a wretched state. Every form of scurvy $I$ saw, from the simple case to those complicated with diarrhœa, dysentery, fever, pneumonia, sloughing ulcers, \&c.

There was one case of gun-shot wound of a peculiarly inter esting character, in which the ball had entered the left thigh, just below the trochanter major, had passed through the limb without injuring the bone or vessels, entered the scrotum near the root of the penis, passed through the scrotum, entered the right thigh, passed to within an inch of its outer external surface, not injuring the bone or vessels, and had been removed by the surgeon under whose care the patient was. It was ten days since the injury at the time I saw him; he appeared in a favourable state for recovery.

The wards appeared very clean; each patient was lying on a woollen bed, with a straw mattress. Hooper's water-cushions were in abundance, and in use where required; indeed, every appliance in medicine and surgery appeared to be at hand. A great deal must no doubt have been done within the last three months to soften Mohammedan prejudices, but there remains still much to be done for the Turkish soldiers.

At the Tent Hospital, situate near Franga-a pretty village two and a half miles distant, 1000 feet above the level of the sea-are 240 convalescents, many of whom will be soon fit to join their regiments in the Crimea. The journey to it is pleasing in the extreme, and from its favourable situation bears much the same ratio in healthfulness to Varna as the Castle 